University of South Florida

DIGITAL COMMONS

Digital Commons @ University of

@ UNIVERSITY OF SOUTH FLORIDA

South Florida

School of Geosciences Faculty and Staff

Publications

School of Geosciences

$9-2013$

\title{
Insights into Distributed Plate Rates across the Walker Lane from GPS Geodesy
}

Zachery M. Lifton

Georgia Institute of Technology

Andrew V. Newman

Georgia Institute of Technology

Kurt L. Frankel

Georgia Institute of Technology

Christopher W. Johnson

Georgia Institute of Technology

Timothy H. Dixon

University of South Florida, thd@usf.edu

Follow this and additional works at: https://digitalcommons.usf.edu/geo_facpub

Part of the Earth Sciences Commons

\section{Scholar Commons Citation}

Lifton, Zachery M.; Newman, Andrew V.; Frankel, Kurt L.; Johnson, Christopher W.; and Dixon, Timothy H., "Insights into Distributed Plate Rates across the Walker Lane from GPS Geodesy" (2013). School of Geosciences Faculty and Staff Publications. 1544.

https://digitalcommons.usf.edu/geo_facpub/1544

This Article is brought to you for free and open access by the School of Geosciences at Digital Commons @ University of South Florida. It has been accepted for inclusion in School of Geosciences Faculty and Staff Publications by an authorized administrator of Digital Commons @ University of South Florida. For more information, please contact digitalcommons@usf.edu. 


\title{
Insights into distributed plate rates across the Walker Lane from GPS geodesy
}

\author{
Zachery M. Lifton, ${ }^{1}$ Andrew V. Newman, ${ }^{1}$ Kurt L. Frankel, ${ }^{1}$ Christopher W. Johnson, ${ }^{1}$ \\ and Timothy H. Dixon ${ }^{2}$ \\ Received 7 June 2013; revised 26 July 2013; accepted 30 July 2013; published 13 September 2013.
}

[1] Contemporary geodetic slip rates are observed to be approximately two times greater than late Pleistocene geologic slip rates across the southern Walker Lane. Using a dense GPS network, we compare the present-day crustal velocities to observed geologic slip rates in the region. We find that the Walker Lane is characterized by a smooth transition from westward extension in the Basin and Range to northwestward motion of the Sierra Nevada block. The GPS velocity field indicates that (1) plate parallel $\left(\mathrm{N} 37^{\circ} \mathrm{W}\right)$ velocities define a velocity differential of $10.6 \pm 0.5 \mathrm{~mm} / \mathrm{yr}$ between the western Basin and Range and the Sierra Nevada block, (2) there is $\sim 2 \mathrm{~mm} / \mathrm{yr}$ of contemporary extension perpendicular to the normal faults of the Silver Peak-Lone Mountain extensional complex, and (3) most of the observed discrepancy in long- and short-term slip rates occurs across Owens Valley. We believe the discrepancy is due to distributed strain and underestimated geologic slip rates. Citation: Lifton, Z. M., A. V. Newman, K. L. Frankel, C. W. Johnson, and T. H. Dixon (2013), Insights into distributed plate rates across the Walker Lane from GPS geodesy, Geophys. Res. Lett., 40, 4620-4624, doi:10.1002/grl.50804.

\section{Introduction}

[2] The southern Walker Lane is a diffuse right-lateral shear zone comprising strike-slip faults and extensional step-overs that extends from the Garlock Fault north to the Mina Deflection and is thought to accommodate $\sim 20 \%$ of the relative motion between the North American and Pacific plates [Dokka and Travis, 1990; Bennett et al., 2003; Wesnousky, 2005; Hammond and Thatcher, 2007]. However, within parts of the southern Walker Lane the contemporary geodetic deformation rate is $\sim 2$ times higher than the geologic fault slip rate over the late Pleistocene. We use GPS data from a dense network of sites to determine specifically where the observed discrepancy occurs between geologic and geodetic slip rates. In particular, we are testing the hypotheses that (1) some of the "missing" slip is taken

Additional supporting information may be found in the online version of this article.

${ }^{1}$ School of Earth and Atmospheric Sciences, Georgia Institute of Technology, Atlanta, Georgia, USA. USA.

${ }^{2}$ Department of Geology, University of South Florida, Tampa, Florida,

Corresponding author: Z. M. Lifton, School of Earth and Atmospheric Sciences, Georgia Institute of Technology, 311 Ferst Dr., Atlanta, GA 30332-0340, USA. (zlifton@gatech.edu)

(C)2013. American Geophysical Union. All Rights Reserved. 0094-8276/13/10.1002/grl.50804 up in the Silver Peak-Lone Mountain extensional complex (SPLM) and (2) much of the discrepancy between geodetic and geologic slip rates occurs in Owens Valley, particularly on the White Mountain Fault (WMF).

[3] The two main structures in the southern Walker Lane are the Northern Death Valley-Fish Lake Valley Fault (DVFLVF) and the WMF (Figure 1a), which accommodate $2.5-3.5$ and $0.3-0.4 \mathrm{~mm} / \mathrm{yr}$ of slip, respectively, over geologic timescales. [Frankel et al., 2011; Kirby et al., 2006]. Shear zone-parallel extension on normal faults within the SPLM accommodate $0.3-2.0 \mathrm{~mm} / \mathrm{yr}$ [Reheis and Sawyer, 1997; Hoeft and Frankel, 2010; Foy et al., 2012]. Some dextral shear may also be accommodated on normal faults west of the WMF, such as the Fish Slough Fault, the normal faults of the Volcanic Tableland, and the Round Valley Fault. However, these are almost all normal faults accommodating extension perpendicular to the strike of the shear zone [Sheehan, 2007]. The Round Valley Fault shows evidence of right-lateral slip, but there is currently no age constraint on the offset landform [Phillips and Majkowski, 2011]. Thus, the total late Pleistocene right-lateral slip rate summed across the southern Walker Lane at $\sim 37.5^{\circ} \mathrm{N}$ is $\sim 3.0-5.9 \mathrm{~mm} / \mathrm{yr}$, while the geodetic rate measured with GPS across the same region was observed to be $\sim 9-10 \mathrm{~mm} / \mathrm{yr}$ [Dixon et al., 2000; Bennett et al., 2003].

[4] Previous studies have estimated the geodetic deformation rate across the evolving, diffuse Pacific-North American plate boundary east of the San Andreas Fault system. Hearn and Humphreys [1998] modeled VLBI and sparse GPS data to estimate a velocity differential of $10.8 \pm 1.5+\mathrm{mm} / \mathrm{yr}$ (no uncertainty reported; we estimated uncertainty from original data) across the southern Walker Lane between the Owens Valley Radio Observatory and the Garlock Fault. Gan et al. [2000] used a transect of GPS stations at approximately $36.5^{\circ} \mathrm{N}$ to estimate a velocity differential across the Walker Lane of $10.3 \pm 4 \mathrm{~mm} / \mathrm{yr}$ (our estimate of uncertainty from original data). In estimating the rigidity and motion of the Sierra Nevada block, Dixon et al. [2000] used several campaign sites at $\sim 37.5^{\circ} \mathrm{N}$, which we have subsequently resurveyed, to estimate a velocity differential across the Walker Lane of 11 $\pm 1 \mathrm{~mm} / \mathrm{yr}$. Bennett et al. [2003] combined the GPS data of Gan et al. [2000] and Dixon et al. [2000] with GPS data from numerous sites in central and northern Nevada to estimate a Walker Lane velocity of $9.3 \pm 0.2 \mathrm{~mm} / \mathrm{yr}$. McCaffrey [2005] estimated $11.3 \pm 0.3 \mathrm{~mm} / \mathrm{yr}$ of relative motion across the eastern California shear zone at $36^{\circ} \mathrm{N}$. Hammond and Thatcher [2007] used campaign GPS data along a transect at $\sim 38.5^{\circ} \mathrm{N}$ to estimate $\sim 10 \mathrm{~mm} / \mathrm{yr}$ (no uncertainty reported) of deformation across the Walker Lane. Further north, at $\sim 39^{\circ} \mathrm{N}$, Wesnousky et al. [2012] estimate 

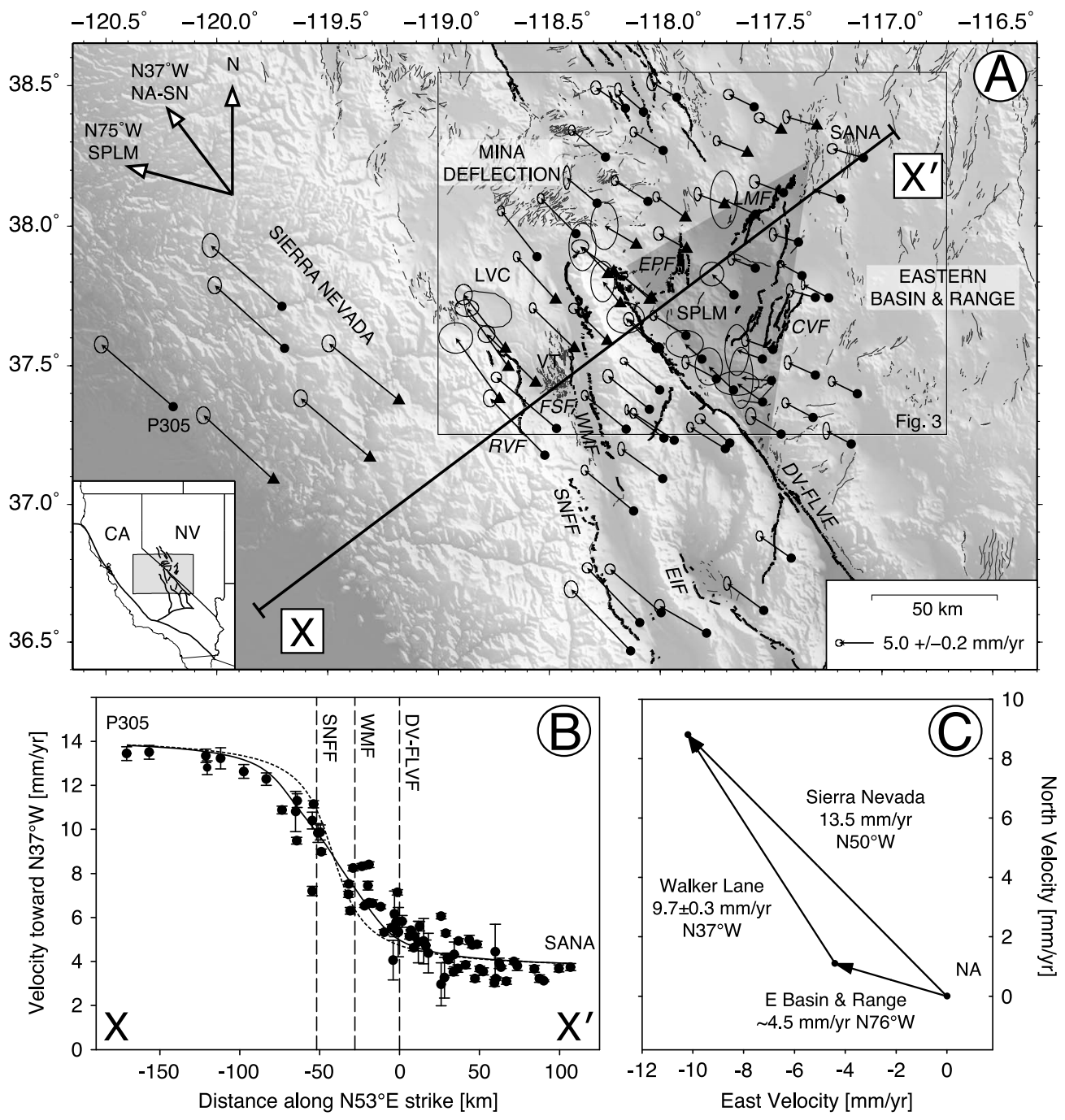

Figure 1. (a) GPS velocity field across the southern Walker Lane. All velocities are relative to stable North America (ITRFNA2005; [DeMets et al., 2010]). Error ellipses represent 2- $\sigma$ uncertainties. Solid gray lines are Quaternary or younger faults. Triangles are sites used in Figure 2. Local plate motion is $\mathrm{N} 37^{\circ} \mathrm{W}$; direction of fault-perpendicular extension in the Silver Peak-Lone Mountain extensional complex is $\mathrm{N}^{\circ} 5^{\circ} \mathrm{W}$. CVF - Clayton Valley Fault; DV-FLVF-Death Valley-Fish Lake Valley Fault; EIF-Eastern Inyo Fault; EPF-Emigrant Peak Fault; FSF-Fish Slough Fault; LMF-Lone Mountain Fault; LVC-Long Valley Caldera; RVF-Round Valley Fault; SNFF—Sierra Nevada Frontal Fault; SPLM—Silver Peak-Lone Mountain extensional complex (gray shaded region); VT-Volcanic Tableland; WMF-White Mountains Fault. (b) Profile of plate-parallel (toward N $37^{\circ} \mathrm{W}$ ) GPS velocities for all sites projected onto a plate-normal transect across the southern Walker Lane. Positions of major faults crossed by the transect are shown with dashed lines. Solid curve is the preferred dislocation model for the three faults shown (locking depth $=15 \mathrm{~km}$, far field velocity $=10.6 \pm 0.5 \mathrm{~mm} / \mathrm{yr}$ ). Dashed curve is the dislocation model for a single fault with the same far field velocity and locking depth. Error bars represent $2-\sigma$ uncertainties. (c) Velocity vector diagram for Walker Lane. Sierra Nevada block velocity was estimated by averaging the velocity relative to North America of six PBO continuous sites in the Sierra Nevada. The azimuth of Walker Lane motion is assumed to be parallel to local plate motion of $\mathrm{N} 37^{\circ} \mathrm{W}$; magnitude of Walker Lane motion is the difference between the furthest northeastern and furthest southwestern GPS sites along the plate normal transect (1b).

right-lateral shear of 5-6 mm/yr along a $120 \mathrm{~km}$ long transect across the Walker Lane.

\section{Data}

[5] We surveyed 48 campaign monuments across the southern Walker Lane in 2010, 2011, and 2012 using Trimble R7 receivers and precision fixed-height spike-mounts $(0.500 \mathrm{~m})$ (Table S1 in the supporting information). Campaign monuments included 26 Mobile Array of GPS for Nevada
Transtension (MAGNET) monuments, 12 existing monuments that were surveyed as early as 1994, and 10 new monuments installed for this study. Resurveying existing campaign monuments extends station time series, which improves velocity estimates. Monuments were observed for a minimum of $72 \mathrm{~h}$ in each campaign. We combined these new campaign data with newly processed data from 28 Plate Boundary Observatory (PBO) continuous GPS stations to create a dense GPS network of 76 sites with an average spacing of $\sim 10 \mathrm{~km}$ (Figure 1a). GPS data were processed using GIPSY/OASIS 

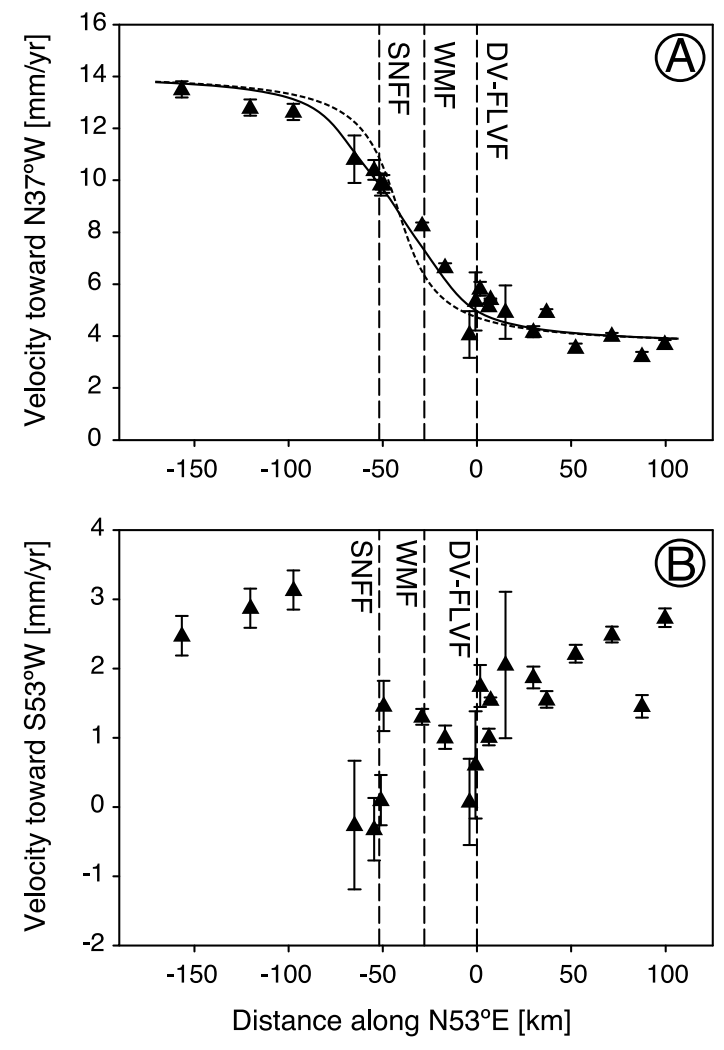

Figure 2. (a) Plate-parallel and (b) plate normal velocity profiles across the Walker Lane along transects perpendicular to plate motion, from a subset of the total data set. Dashed vertical lines represent the location of major faults across the transect. Solid curve and dashed curve are the same solutions as shown in Figure 1b. SNFF-Sierra Nevada Frontal Fault; WMF-White Mountains Fault; DV-FLVF -Death Valley-Fish Lake Valley Fault.

II software with precise point positioning [Zumberge et al., 1997]. All velocities are calculated in ITRF2005 relative to stable North America, with an Euler pole of $-6.8^{\circ},-84.8^{\circ}$ rotating $0.189^{\circ} \mathrm{My}^{-1}$ (NA-ITRF2005, [DeMets et al., 2010]). The location, velocity, and uncertainty for all GPS sites are presented in Table S1 in the supporting information.

[6] We evaluated the horizontal component of the GPS velocities relative to the strike of plate motion between the Sierra Nevada block and the western Basin and Range $\left(\mathrm{N} 37^{\circ} \mathrm{W}\right)$, which coincides with the strike of the DV-FLVF [Bennett et al., 2003]. In addition, we evaluated the SPLM velocity field relative to the direction of extension on SPLM normal faults striking $\sim 15^{\circ}$.

\section{Results}

[7] The projected velocity fields (Figure 1a) show characteristic patterns of distributed shear zone deformation. From east to west across the southern Walker Lane, velocities increase in magnitude and rotate from west-northwest to northwest, reflecting a large diffuse fault zone demarking the transition from Basin and Range to Sierra Nevada block. The northwestward velocity reaches a maximum for sites located on the rigid Sierra Nevada block that are moving nearly uniformly to the northwest [Dixon et al., 2000]. When GPS velocities are reprojected to the local plate motion, $\mathrm{N} 37^{\circ} \mathrm{W}$, the fault parallel velocities across the southern Walker Lane steadily increase along a plate perpendicular transect from northeast to southwest as the sites are located progressively further onto the Pacific plate side of the diffuse boundary (Figure 1b). Although the transect crosses the DVFLVF, the WMF, and the SNFF, the velocity profile is broad and smooth and contributions of individual faults are obscured by close spacing between faults, as we discuss below.

[8] Dislocation modeling of slip on individual faults in the Walker Lane requires a solution that combines interseismic contributions from several faults. With current station spacing, the velocity gradient across the Walker Lane appears too smooth to identify deformation signals from multiple adjacent faults. We used a modified form of the Savage and Burford [1973] vertical strike-slip dislocation model that includes the contribution of individual offset faults [e.g., Dixon et al., 1995], to account for locking across each the SNFF, WMF, and DV-FLVF. Because of the proximity of faults, useful solutions for locking depths were not possible, and hence we fixed the value to be $15 \mathrm{~km}$ for all faults - the depth above which $99 \%$ of all observed seismicity in the region has been observed (ANSS Worldwide Earthquake Catalog, accessed 22 April 2013). For comparison we also model the best fit solution for a single fault, also with a $15 \mathrm{~km}$ locking depth. A slight positive apparent shift of the models relative to the southwestern limb is the result of increased data density near the center and northeastern limb. While the solutions for both models are equivalent away from the faults, finding a far field velocity of $10.6 \pm$ $0.5 \mathrm{~mm} / \mathrm{yr}$, the distributed faults model more closely matches the approximately linear trend in the near-field GPS data (Figure 1b). The modeled far field velocity $(10.6 \pm 0.5 \mathrm{~mm} / \mathrm{yr})$ is slightly higher than the observed maximum GPS offset $(9.7 \pm 0.3 \mathrm{~mm} / \mathrm{yr}$, see below) because the model predicts modest interseismic strain accumulation outside the most distal data points we measured. We did not use the measured far field velocity to constrain our model because it would require an unreasonably shallow locking depth. When the San Andreas Fault is included in the dislocation model, its interseismic strain accumulation does not affect our sites in the Walker Lane (Figure S1 in the supporting information).

[9] The average velocity of six continuous GPS sites (P245, P305, P512, P629, P725, and MUSB) located on the interior of the Sierra Nevada block is $13.5 \pm 0.5 \mathrm{~mm} / \mathrm{yr}$ toward $\mathrm{N} 50^{\circ} \mathrm{W}$ relative to North America, which we use to define the rigid Sierra Nevada block. This velocity encompasses the complete available translation rate expected across the Walker Lane and Basin and Range. The total velocity gradient across the southern Walker Lane at $\sim 37.5^{\circ} \mathrm{N}$, calculated from the difference in plate parallel velocity between P305 and SANA (Figures 1a and 1b), the two most distal sites perpendicular to plate motion, is $9.7 \pm 0.3 \mathrm{~mm} / \mathrm{yr}$ toward $\mathrm{N} 37^{\circ} \mathrm{W}$. Removing the Walker Lane vector from the Sierra Nevada vector yields the remaining velocity between the central Basin and Range (site SANA) and North America, $\sim 4.5 \mathrm{~mm} / \mathrm{yr}$ toward $\mathrm{N} 76^{\circ} \mathrm{W}$ (Figure $1 \mathrm{c}$ ).

[10] Subsets of the velocity field, which sample narrower swaths, define details of plate-parallel and plate-normal velocity profiles perpendicularly across the southern Walker Lane (Figure 2 and Figure S2 in the supporting information). The velocity profile in Figure 2a is the longest profile across the southern Walker Lane and includes sites on 

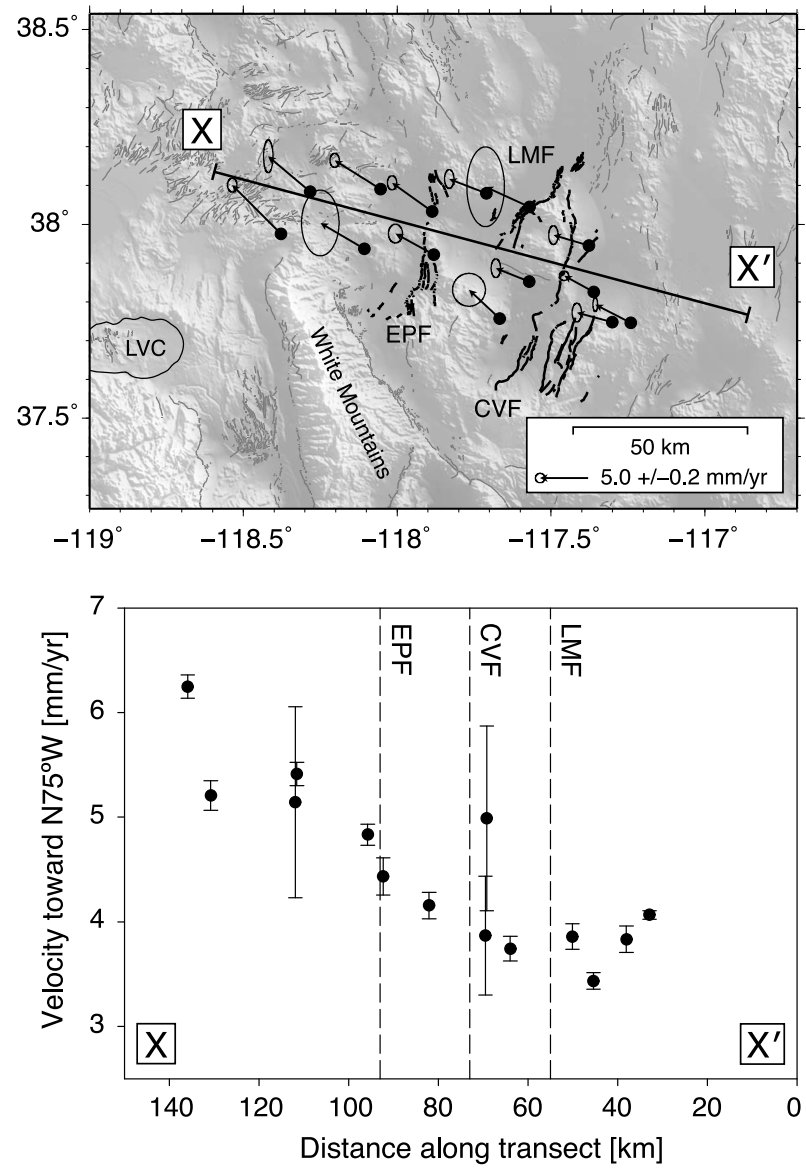

Figure 3. (a) Shaded relief map of the SPLM showing GPS velocities and location of transect perpendicular to the strike of SPLM normal faults $\left(\sim 15^{\circ}\right)$. (b) SPLM extension-parallel velocity profile corresponding to transect line in (a). Velocity profile shows extension-parallel velocity increasing toward $\mathrm{N} 75^{\circ} \mathrm{W}$, suggesting that there is active extensional deformation occurring across the SPLM. CVF-Clayton Valley Fault; EPF-Emigrant Peak Fault; LMF-Lone Mountain Fault.

the interior of the Sierra Nevada block. The velocity gradient has nearly constant velocity at either end of the profile, smooth transitions at $\sim-60$ and $\sim 10 \mathrm{~km}$, and a steep velocity gradient across the middle of the profile. Additional subset velocity profiles can be found in Figure S2 in the supporting information. A notable feature of almost all the subset profiles is the nearly linear velocity gradient across the shear zone.

[11] Viewing the SPLM GPS velocities reprojected to $\mathrm{N} 75^{\circ} \mathrm{W}$, the direction of extension perpendicular to the average strike of normal faults, illuminates the nearly linear velocity gradient increasing from SE to NW (Figure 3). This increase in velocity in the direction of extension suggests the SPLM is undergoing active diffuse extension.

\section{Discussion}

[12] Understanding geodetic rates of deformation at higher spatial resolution has implications for resolving the discrepancy between short- and long-term slip rates in the southern Walker Lane. By estimating deformation in smaller regions or across individual faults, we can see where geodetic rates are elevated and predict where geologic rates are likely underestimated. Geologic slip rates can underestimate the strain field in a number of ways. For example, deformation may be distributed off major faults, which leads to underestimated offsets. In addition, some deformation, whether distributed or concentrated on faults, may not be preserved in the geologic record when erosion or scarp degradation occurs. This is particularly problematic in large basins filled with unconsolidated alluvium, as in the Basin and Range.

[13] Late Pleistocene geologic extension rates across the SPLM include $0.1-1.3 \mathrm{~mm} / \mathrm{yr}$ on the Emigrant Peak Fault [Reheis and Sawyer, 1997], $0.1-0.4 \mathrm{~mm} / \mathrm{yr}$ on the Lone Mountain Fault [Hoeft and Frankel, 2010], and 0.1-0.3 mm/yr on the Clayton Valley Fault [Foy et al., 2012], for a total sum of $0.3-2.0 \mathrm{~mm} / \mathrm{yr}$. This wide range of possible rates makes it difficult to constrain the discrepancy between longand short-term rates, but the maximum is remarkably similar to the $\sim 2 \mathrm{~mm} / \mathrm{yr}$ of contemporary extensional deformation we observed (Figure 3). Thus, if we assume the maximum extension rates on these faults reflect the true slip rates, our data suggest that distributed extension in the SPLM is likely not causing the majority of the observed discrepancy in long- and short-term slip rates. Instead, we find the discrepancy exists across Owens Valley. The plate-parallel GPS velocity gradient across Owens Valley is $\sim 2 \mathrm{~mm} / \mathrm{yr}$, while the sum of the late Pleistocene rightlateral slip rates is $0.3-0.4 \mathrm{~mm} / \mathrm{yr}$ [Kirby et al., 2006]. Lee et al. [2001] estimated right-lateral slip on the Owens Valley Fault (OVF) to be $1.8-3.6 \mathrm{~mm} / \mathrm{yr}$ over the Holocene, and proposed that right-lateral slip from the OVF was transferred to the WMF further north. Kirby et al. [2008] estimated even faster late Pleistocene rightlateral slip rates on the OVF between 2.8 and $4.5 \mathrm{~mm} / \mathrm{yr}$. If OVF slip transfers north to the WMF, then the discrepancy may range from zero (fully reconciled) to as much as $\sim 4.0 \mathrm{~mm} / \mathrm{yr}$ of slip that is not accounted for at the latitude of the WMF. The discrepancy here between long- and short-term rates can be the result of several possible factors: (1) geologic slip rates are underestimated, (2) deformation in Owens Valley is distributed among many small structures and a complete record of slip is not preserved, (3) transfer of slip to the west or northwest [e.g., Nagorsen-Rinke et al. [2013] or (4) Owens Valley is currently experiencing a transient increase in strain. Since long- and short-term slip rates agree in other parts of the Walker Lane, suggesting an absence of transient strain, we favor some combination of the first three factors rather than transient increases in strain rate as an explanation for the discrepancy in Owens Valley. "Missing" slip in the long-term record is more likely broadly distributed deformation on small or poorly preserved structures [e.g., Foy et al., 2012] or underestimated on known structures. The scarcity of quantitative slip rate estimates on the WMF makes it difficult to evaluate the accuracy of previous estimates there, but geomorphic evidence suggests that the west side of the White Mountains has experienced significant tectonic activity. Furthermore, the smooth GPS velocity gradient across the White Mountains block suggests slip is partitioned nearly equally on either side. Yet, right-lateral slip rate estimates at the same latitude on the FLV, which bounds the east side of the White Mountains, are considerably higher $(2.5-3 \mathrm{~mm} / \mathrm{yr}$ [Frankel et al., 2011]) than the rate on the WMF $(0.3-0.4 \mathrm{~mm} / \mathrm{yr}$ 
[Kirby et al., 2006]). Thus, late Pleistocene slip rates on the WMF are likely underestimated.

[14] Other factors may contribute to the discrepancy in long- and short-term slip rates. For example, postseismic effects of the 1872 Mw7.6 Owens Valley earthquake may increase the observed contemporary geodetic slip rates because strain accumulation is faster at the beginning of the earthquake cycle [e.g., Hammond et al., 2009; Dixon et al., 2003]. However, while some layered viscoelastic dislocation models can account for postseismic relaxation and predict slip rates that agree with long-term geologic slip rates [e.g., Savage and Lisowski, 1998], we believe postseismic effects are not contributing much to the discrepancy because other regions of the Walker Lane-eastern California shear zone that should be similarly affected exhibit no discrepancy between long- and short-term slip rates. Furthermore, the long time series from continuous GPS stations in the region show a clear linear trend in displacement over at least the last $\sim 10$ years.

\section{Conclusions}

[15] Using a dense GPS network across the southern Walker Lane, we investigate the previously observed discrepancy in long- and short-term slip rates. We find that the southern Walker Lane at $\sim 37.5^{\circ} \mathrm{N}$ accommodates $10.6 \pm 0.5 \mathrm{~mm} / \mathrm{yr}$ of right-lateral slip along the local plate motion direction of $\mathrm{N} 37^{\circ} \mathrm{W}$, the SPLM is currently undergoing $\sim 2 \mathrm{~mm} / \mathrm{yr}$ of extensional deformation toward $\mathrm{N} 75^{\circ} \mathrm{W}$, and Owens Valley accommodates $\sim 2 \mathrm{~mm} / \mathrm{yr}$ of contemporary right-lateral deformation, compared to $0.4 \mathrm{~mm} / \mathrm{yr}$ of slip during the late Pleistocene. We conclude that contemporary rates of extension across the SPLM are equivalent to maximum late Pleistocene rates of extension and that the observed discrepancy between contemporary geodetic and long-term geologic slip rates across the southern Walker Lane is occurring somewhere in Owens Valley. The discrepancy is likely a combination of underestimated geologic slip rates on the WMF and broadly distributed deformation in Owens Valley that is not well preserved in the geologic record.

[16] Acknowledgments. This study was funded by NSF grant EAR0948570, a White Mountains Research Station minigrant, a GSA research grant, a Sigma Xi grant-in-aid of research, and Georgia Tech Foundation. This material is based in part on equipment provided by UNAVCO with support from NSF and NASA under NSF EAR-0735156 and on data provided by the EarthScope Plate Boundary Observatory supported by NSF EAR-0350028 and EAR-0732947. We thank A. Foy for assistance with campaign surveys. Special thanks to W. Hammond and G. Blewitt for loan of MAGNET monument adapters and permission to occupy their regional network.

[17] The Editor thanks Wayne Thatcher and an anonymous reviewer for their assistance in evaluating this manuscript.

\section{References}

Bennett, R., B. Wernicke, N. Niemi, A. Friedrich, and J. Davis (2003), Contemporary strain rates in the northern Basin and Range province from GPS data, Tectonics, 22(2), 1008, doi:10.1029/2001TC001355.

DeMets, C., R. G. Gordon, and D. F. Argus (2010), Geologically current plate motions, Geophys. J. Int., 181(1), 1-80, doi:10.1111/j.1365246X.2009.04491.x.

Dixon, T. H., S. Robaudo, J. Lee, and M. C. Reheis (1995), Constraints on present-day Basin and Range deformation from space geodesy, Tectonics, 14(4), 755-772.

Dixon, T. H., M. Miller, F. Farina, H. Wang, and D. Johnson (2000), Present-day motion of the Sierra Nevada block and some tectonic implications for the Basin and Range province, North America, Tectonics, 19, 1-24.

Dixon, T. H., E. Norabuena, and L. Hotaling (2003), Paleoseismology and Global Positioning System: Earthquake-cycle effects and geodetic versus geologic fault slip rates in the eastern California shear zone, Geology, $31(1), 55-58$

Dokka, R. K., and C. J. Travis (1990), Late Cenozoic strike-slip faulting in the Mojave Desert, California, Tectonics, 9(2), 311-340.

Foy, T. A., K. L. Frankel, Z. M. Lifton, C. W. Johnson, and M. W. Caffee (2012), Distributed extensional deformation in a zone of right-lateral shear: Implications for geodetic versus geologic rates of deformation in the eastern California shear zone-Walker Lane, Tectonics, 31, TC4008, doi:10.1029/2011TC002930.

Frankel, K. L., J. F. Dolan, L. A. Owen, P. Ganev, and R. C. Finkel (2011), Spatial and temporal constancy of seismic strain release along an evolving segment of the Pacific-North America plate boundary, Earth Planet. Sci. Lett., 304(3-4), 565-576, doi:10.1016/j.eps1.2011.02.034.

Gan, W., J. Svarc, J. Savage, and W. Prescott (2000), Strain accumulation across the Eastern California Shear Zone at latitude $36^{\circ} 30^{\prime} \min \mathrm{N}, J$. Geophys. Res., 105, 16.

Hammond, W. C., and W. Thatcher (2007), Crustal deformation across the Sierra Nevada, northern Walker Lane, Basin and Range transition, western United States measured with GPS, 2000-2004, J. Geophys. Res., 112, B05411, doi:10.1029/2006JB004625.

Hammond, W. C., C. Kreemer, and G. Blewitt (2009), Geodetic constraints on contemporary deformation in the northern Walker Lane: 3. Central Nevada seismic belt postseismic relaxation, in Late Cenozoic Structure and Evolution of the Great Basin-Sierra Nevada Transition: Geological Society of America Special Paper, vol. 447, edited by J. S. Oldow and P. H. Cashman, 33-54, Geol. Soc. of Am., Boulder, Colo, doi:10.1130/ 2009.2447(03).

Hearn, E. H., and E. D. Humphreys (1998), Kinematics of the southern Walker Lane Belt and motion of the Sierra Nevada block, California, J. Geophys. Res., 103(B11), 27,033-27,049.

Hoeft, J. S., and K. L. Frankel (2010), Temporal variations in extension rate on the Lone Mountain fault and strain distribution in the eastern California shear zone-Walker Lane, Geosphere, 6(6), 917-936, doi:10.1130/ GES00603.S2.

Kirby, E., D. W. Burbank, M. Reheis, and F. Phillips (2006), Temporal variations in slip rate of the White Mountain Fault Zone, Eastern California, Earth Planet. Sci. Lett., 248(1-2), 168-185, doi:10.1016/j. eps1.2006.05.026.

Kirby, E., S. Anandakrishnan, F. Phillips, and S. Marrero (2008), Late Pleistocene slip rate along the Owens Valley fault, eastern California, Geophys. Res. Lett., 35, L01304, doi:10.1029/2007GL031970.

Lee, J., J. Spencer, and L. Owen (2001), Holocene slip rates along the Owens Valley fault, California: Implications for the recent evolution of the Eastern California Shear Zone, Geology, 29(9), 819

McCaffrey, R. (2005), Block kinematics of the Pacific-North America plate boundary in the southwestern United States from inversion of GPS, seismological, and geologic data, J. Geophys. Res., 110, B07401, doi:10.1029/ 2004JB003307.

Nagorsen-Rinke, S., J. Lee, and A. Calvert (2013), Pliocene sinistral slip across the Adobe Hills, eastern California-western Nevada: Kinematics of fault slip transfer across the Mina deflection, Geosphere, 9(1), 37-53, doi:10.1130/GES00825.S3.

Phillips, F. M., and L. Majkowski (2011), The role of low-angle normal faulting in active tectonics of the northern Owens Valley, California, Lithosphere, 3(1), 22-36, doi:10.1130/L73.1.

Reheis, M. C., and T. L. Sawyer (1997), Late Cenozoic history and slip rates of the Fish Lake Valley, Emigrant Peak, and Deep Springs fault zones, Nevada and California, Geol. Soc. Am. Bull., 109(3), 280-299, doi:10.1130/ 0016-7606(1997)109<0280:LCHASR > 2.3.CO;2.

Savage, J. C., and R. O. Burford (1973), Geodetic determination of relative plate motion in central California, J. Geophys. Res., 78(5), 832-845.

Savage, J. C., and M. Lisowski (1998), Viscoeleastic coupling model of the San Andreas Fault along the big bend, southern California, J. Geophys. Res., 103(B4), 7281-7292.

Sheehan, T. P. (2007), Evolution of Neogene Fault Populations in Northern Owens Valley, California and Implications for the Eastern California Shear Zone, Ph.D. thesis, School of Science and Engineering, Tulane University, New Orleans, Louisiana.

Wesnousky, S. G. (2005), The San Andreas and Walker Lane fault systems, western North America: Transpression, transtension, cumulative slip and the structural evolution of a major transform plate boundary, J. Struct. Geol., 27(8), 1505-1512, doi:10.1016/j.jsg.2005.01.015.

Wesnousky, S. G., J. M. Bormann, C. Kreemer, W. C. Hammond, and J. N. Brune (2012), Neotectonics, geodesy, and seismic hazard in the Northern Walker Lane of Western North America: Thirty kilometers of crustal shear and no strike-slip?, Earth Planet. Sci. Lett., 329, 133-140, doi:10.1016/j.eps1.2012.02.018.

Zumberge, J., M. Heflin, D. Jefferson, M. Watkins, and F. Webb (1997), Precise point positioning for the efficient and robust analysis of GPS data from large networks, J. Geophys. Res., 102, 5005-5018. 